\title{
Mathematical modeling of the short-term performance of railway track under train induced loading
}

\author{
Piyush Punetha ${ }^{1[0000-0002-0812-4708]}$, and Sanjay Nimbalkar ${ }^{1[0000-0002-1538-3396]}$ \\ ${ }^{1}$ School of Civil and Environmental Engineering, FEIT, University of Technology Sydney,
} NSW-2007, Australia

\begin{abstract}
The accurate prediction of the track deformation under train induced repetitive loading is inevitable to assess the efficiency of a railway track. This paper presents an analytical technique to calculate the transient deformations in a railway track subjected to train induced loading. The method considers the track substructure as multi-layered media in which the behavior of an individual track layer is simulated using a mass-spring-dashpot model. Unlike existing approaches to model the track substructure as an equivalent single or double layer, the proposed analytical approach considers all the three layers of the ballasted track (i.e., ballast, capping or subballast and subgrade). The accuracy of the proposed technique is investigated by comparing the predicted values of track settlement with the published data available in the literature. The predicted results are found to be in good agreement with past studies. A parametric study on the substructure behavior revealed that the elastic modulus of track layers significantly influences the track response.
\end{abstract}

Keywords: Mathematical model, Recoverable Deformation, Railway Track.

\section{Introduction}

With an increase in demand for higher speed, the stress and deformations in the ballasted tracks have increased substantially [1]. To maintain an adequate level of passenger safety and comfort necessary for high-speed rail operations, the frequency of maintenance activities has increased manifolds. These maintenance operations are usually expensive due to poor understanding of the track behavior, inadequate planning, lack of time for the analysis of track inspection data or unavailability of an adequate database [2]. Thus, an accurate evaluation of the track substructure response is essential to plan the maintenance cycles and optimize track performance. The development of a reliable technique for prediction of track response would lead to significant cost savings in the operation of the railways at elevated train speed.

The field studies, laboratory investigations, numerical and analytical simulations can be used to understand the behavior of a railway track. The field and reduced scale laboratory investigations with proper instrumentation are reliable approaches to understand the track response. They also provide valuable data that can be used for validating the numerical or analytical models. However, these investigations are usually time con- 
suming and expensive. The numerical and analytical techniques are promising alternatives to analyze the track response. Consequently, several researchers have utilized numerical simulations to evaluate the response of the railway tracks subjected to train induced repeated loads [3-12]. However, the numerical simulation of the railway tracks generally requires enormous computational time and resources.

The analytical techniques are relatively faster than the numerical simulations. Therefore, several researchers have developed analytical methodologies in an attempt to simulate the response of the railway track [13-16]. The track substructure in these methods is modeled using equivalent spring or dashpots, as a half-space (either homogenous or layered) or a combination of these two [17, 18]. Choudhury et al. [19] simulated the response of the railway track using a two degree of freedom mass-spring-dashpot model.

In this paper, a methodology is developed to calculate the transient (recoverable) response of the track substructure layers subjected to train induced repeated loads. The present approach employs a mass-spring-dashpot model to capture the track behavior. The method includes the ballast, capping (also known as subballast) and subgrade layers, and also considers the continuity of these layers in the longitudinal direction. The validity of the proposed technique is examined by comparing the model predictions with the published data available in the literature. Subsequently, a parametric investigation is carried out to study the effect of individual layer properties on the track behavior.

\section{Development of mathematical model to predict the track response}

Fig. 1 represents the schematic diagram of a ballasted railway track structure. It consists of two components: superstructure and substructure. The superstructure comprises of the rails, ties (sleepers), rail pads and fasteners. The substructure is the geotechnical component which comprises of ballast, capping (or subballast) and subgrade layers. To evaluate the transient response, the track substructure is modelled as a three degree of freedom (3DoF) system. Fig. 2 shows the 3DoF mass-spring-dashpot model of the track substructure. Each substructure layer is composed of lumped masses that are supported by visco-elastic elements such as springs and dashpots. 


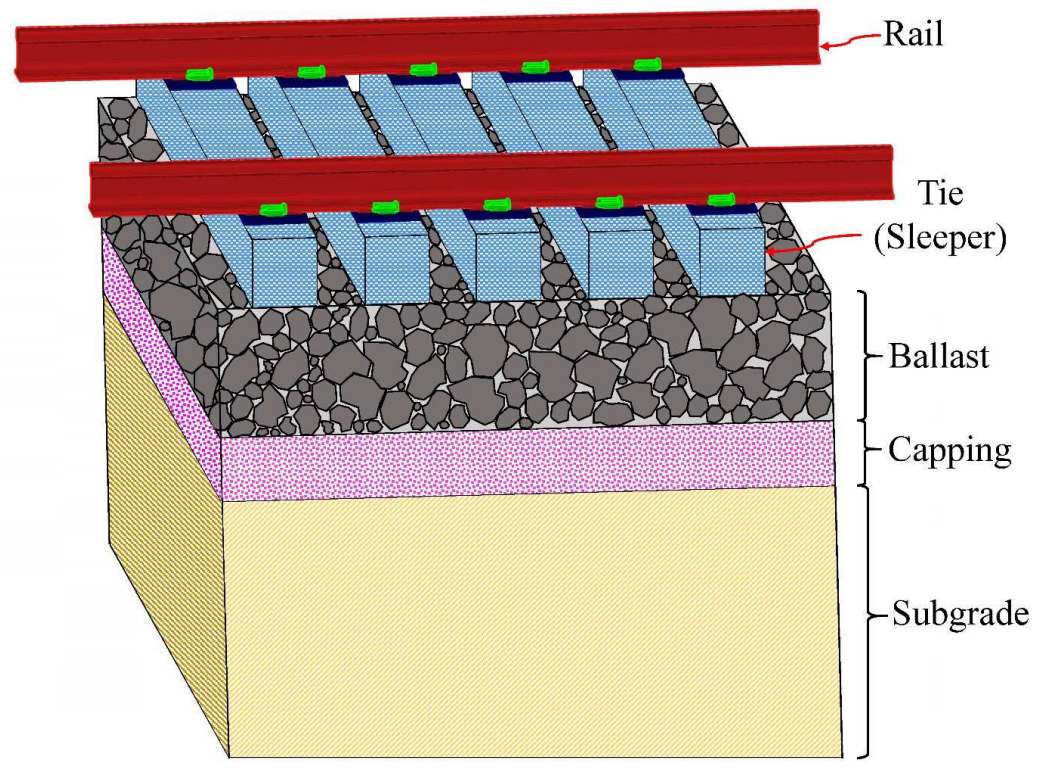

Fig. 1. Structure of a ballasted railway track

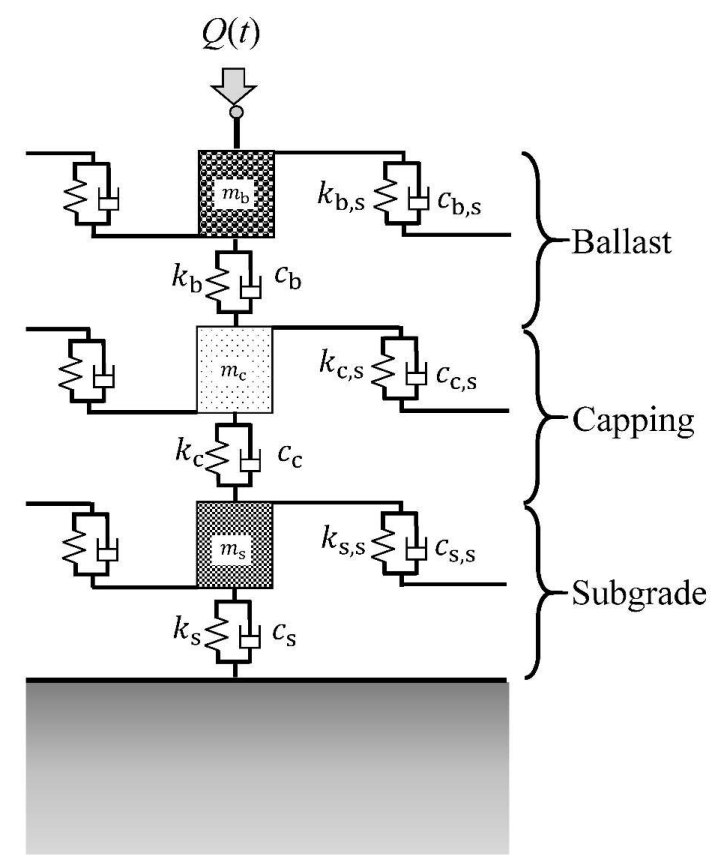

Fig. 2. Mass-spring-dashpot model of the track substructure 
The equation of motion for the track below the $n^{\text {th }}$ tie point is derived by imposing the dynamic equilibrium condition:

$$
M \ddot{Y}_{\mathrm{n}}+C \dot{Y}_{\mathrm{n}}+K Y_{\mathrm{n}}=F_{\mathrm{n}}+C^{s}\left(\dot{Y}_{\mathrm{n}+1}+\dot{Y}_{\mathrm{n}-1}\right)+K^{s}\left(Y_{\mathrm{n}+1}+Y_{\mathrm{n}-1}\right)
$$

where $\boldsymbol{M}, \boldsymbol{C}, \boldsymbol{C}^{\mathrm{s}}, \boldsymbol{K}$ and $\boldsymbol{K}^{\boldsymbol{s}}$ are the mass, damping and stiffness matrices; $\ddot{\boldsymbol{Y}}_{\mathrm{n}}, \dot{\boldsymbol{Y}}_{\mathbf{n}}, \boldsymbol{Y}_{\mathbf{n}}$ and $\boldsymbol{F}_{\mathbf{n}}$ are the acceleration, velocity, displacement and force vectors at the $n^{\text {th }}$ tie, respectively. The Newmark's implicit scheme is used to solve Eq. (1) and evaluate the transient response of the substructure layers in terms of displacement, acceleration and velocity time-histories. The mass, stiffness and damping matrices in Eq. (1) are defined as:

$$
\begin{gathered}
\boldsymbol{M}=\left[\begin{array}{ccc}
m_{\mathrm{s}} & 0 & 0 \\
0 & m_{\mathrm{c}} & 0 \\
0 & 0 & m_{\mathrm{b}}
\end{array}\right] \\
\boldsymbol{C}=\left[\begin{array}{ccc}
c_{\mathrm{s}}+c_{\mathrm{c}}+2 c_{\mathrm{s}, \mathrm{s}} & -c_{\mathrm{c}} & 0 \\
-c_{\mathrm{c}} & c_{\mathrm{c}}+c_{\mathrm{b}}+2 c_{\mathrm{c}, \mathrm{s}} & -c_{\mathrm{b}} \\
0 & -c_{\mathrm{b}} & c_{\mathrm{b}}+2 c_{\mathrm{b}, \mathrm{s}}
\end{array}\right] ; \boldsymbol{C}^{\boldsymbol{s}}=\left[\begin{array}{ccc}
c_{\mathrm{s}, \mathrm{s}} & 0 & 0 \\
0 & c_{\mathrm{c}, \mathrm{s}} & 0 \\
0 & 0 & c_{\mathrm{b}, \mathrm{s}}
\end{array}\right] \\
\boldsymbol{K}=\left[\begin{array}{ccc}
k_{\mathrm{s}}+k_{\mathrm{c}}+2 k_{\mathrm{s}, \mathrm{s}} & -k_{\mathrm{c}} & 0 \\
-k_{\mathrm{c}} & k_{\mathrm{c}}+k_{\mathrm{b}}+2 k_{\mathrm{c}, \mathrm{s}} & -k_{\mathrm{b}} \\
0 & -k_{\mathrm{b}} & k_{\mathrm{b}}+2 k_{\mathrm{b}, \mathrm{s}}
\end{array}\right] ; \boldsymbol{K}^{\boldsymbol{s}}=\left[\begin{array}{ccc}
k_{\mathrm{s}, \mathrm{s}} & 0 & 0 \\
0 & k_{\mathrm{c}, \mathrm{s}} & 0 \\
0 & 0 & k_{\mathrm{b}, \mathrm{s}}
\end{array}\right]
\end{gathered}
$$

where $m_{\mathrm{s}}, m_{\mathrm{c}}$ and $m_{\mathrm{b}}$ are the vibrating mass of subgrade, capping and ballast, respectively; $c_{\mathrm{s}}, c_{\mathrm{c}}$ and $c_{\mathrm{b}}$ are the damping coefficients of subgrade, capping and ballast, respectively; $k_{\mathrm{s}}, k_{\mathrm{c}}$ and $k_{\mathrm{b}}$ are the stiffness of subgrade, capping and ballast, respectively; $k_{\mathrm{s}, \mathrm{s}}, k_{\mathrm{c}, \mathrm{s}} k_{\mathrm{b}, \mathrm{s}}$ are the shear stiffness of subgrade, capping and ballast, respectively; $c_{\mathrm{s}, \mathrm{s}}, c_{\mathrm{c}, \mathrm{s}}$ and $c_{\mathrm{b}, \mathrm{s}}$ are the shear damping coefficients of subgrade, capping and ballast, respectively. The mass and stiffness of the track layers are evaluated by using a pyramidal load distribution model incorporating the overlapping effect along both longitudinal and transverse directions $[20,21]$. The damping coefficients for each layer are evaluated using the principle of vibrations as [22]:

$$
c_{\mathrm{i}}=\sqrt{\frac{E_{\mathrm{i}} \rho_{\mathrm{i}}}{\left(1+v_{\mathrm{i}}\right)\left(1-v_{\mathrm{i}}\right)}}
$$

where $i=b, c$ and $s$ for ballast, capping and subgrade, respectively; $\rho_{\mathrm{i}}$ and $v_{\mathrm{i}}$ are the density and Poisson's ratio of the $i^{\text {th }}$ substructure layer, respectively. The acceleration, velocity, displacement and force vectors are defined as:

$$
\ddot{\boldsymbol{Y}}_{\mathbf{n}}=\left\{\begin{array}{c}
\ddot{y}_{\mathrm{s}, \mathrm{n}}(t) \\
\ddot{y}_{\mathrm{c}, \mathrm{n}}(t) \\
\ddot{y}_{\mathrm{b}, \mathrm{n}}(t)
\end{array}\right\} ; \dot{\boldsymbol{Y}}_{\mathbf{n}}=\left\{\begin{array}{c}
\dot{y}_{\mathrm{s}, \mathrm{n}}(t) \\
\dot{y}_{\mathrm{c}, \mathrm{n}}(t) \\
\dot{y}_{\mathrm{b}, \mathrm{n}}(t)
\end{array}\right\} ; \boldsymbol{Y}_{\mathbf{n}}=\left\{\begin{array}{l}
y_{\mathrm{s}, \mathrm{n}}(t) \\
y_{\mathrm{c}, \mathrm{n}}(t) \\
y_{\mathrm{b}, \mathrm{n}}(t)
\end{array}\right\} ; \boldsymbol{F}_{\mathbf{n}}=\left\{\begin{array}{l}
f_{\mathrm{s}, \mathrm{n}}(t) \\
f_{\mathrm{c}, \mathrm{n}}(t) \\
f_{\mathrm{b}, \mathrm{n}}(t)
\end{array}\right\}
$$


where the subscripts $s, c$ and $b$ represent the subgrade, capping and ballast, respectively; $\ddot{y}, \dot{y}$ and $y$ are the acceleration, velocity and displacement of the track layers, respectively; $f$ is the external load acting on the substructure layer. The external load acting on the capping and subgrade layers at a tie point are taken as zero, whereas, the external load acting on the ballast layer is equal to the rail-seat load. The rail-seat load $[Q(\mathrm{t})]$ is evaluated following the approach given in Doyle [23].

The dynamic effects of the rail-wheel interaction are also incorporated in the analysis using an impact factor $(I F)$ [24], which is a multiplier to the static axle (or wheel) load $\left(Q_{\mathrm{a}}\right)[1]$.

$$
I F=1+\alpha_{1}\left(\frac{V}{D_{\mathrm{w}}}\right)^{\alpha_{2}}
$$

where $V$ and $D_{\mathrm{w}}$ are the train speed, and wheel diameter, respectively; $\alpha_{1}$ and $\alpha_{2}$ are the empirical coefficients.

\section{Verification of the proposed model}

The validity of the proposed technique is examined by comparing the predicted results with the field investigation results reported by Takemiya and Bian [25] and Priest et al. [26]. Takemiya and Bian [25] presented the dynamic response of a high-speed ballasted rail track section located along the West Coast line in Sweden. The track at the test section comprised of $60 \mathrm{~kg} / \mathrm{m}$ rails supported by rail pad, ties, ballast and subgrade layers. The track response was expressed in terms of the vertical displacement and acceleration generated during the passage of a Swedish X-2000 high-speed train.

Fig. 3 compares the Fourier amplitude spectrum of the transient vertical ground displacement calculated using the present approach with the data recorded in the field investigations [25]. The values of the parameters used for the simulation are provided in Table 1. The thickness of top (ballast), middle (capping) and bottom (subgrade) layers are taken as $1,13.5$ and $36 \mathrm{~m}$, respectively. It is shown that the response predicted using the proposed method is nearly identical to that observed in the field investigations. It can also be observed that the response is distributed over a frequency range of 0.1-9 $\mathrm{Hz}$. The peaks are observed in the frequency range between 0.1 and $3 \mathrm{~Hz}$ (due to the combined effect of train geometry and speed), and at 3.2, 3.66, 4.12, 4.73, 5 and $6.7 \mathrm{~Hz}$ (associated with bogie positions).

Priest et al. [26] carried out extensive field investigations in a heavy haul track in South Africa. The track section comprised of $60 \mathrm{~kg} / \mathrm{m}$ rails supported by ties, ballast $(0.3 \mathrm{~m}$ thick) and formation layers. They employed geophones to monitor the velocity and the corresponding displacement of individual track layers. Fig. 4 compares the variation of transient displacement with time during the passage of 20 -tonne axle load wagons, calculated using the present approach with the data recorded in the field investigations. Table 1 provides the values of the parameters employed in simulations. The model predictions slightly underestimate the magnitude of vertical displacement, however, the trend is similar to the field data. 
Table 1. Parameters for evaluating track response

\begin{tabular}{|c|c|c|c|c|c|}
\hline Parameter & Symbol & Unit & $\begin{array}{l}\text { Takemiya } \\
\text { and Bian } \\
{[25]}\end{array}$ & $\begin{array}{l}\text { Priest et al. } \\
{[26]}\end{array}$ & $\begin{array}{l}\text { Parametric } \\
\text { study }\end{array}$ \\
\hline Wheel diameter & $D_{\mathrm{w}}$ & $\mathrm{m}$ & 1.016 & 0.954 & 1.016 \\
\hline Axle load & $Q_{\mathrm{a}}$ & $\mathrm{kN}$ & $118-180$ & 196 & 250 \\
\hline Empirical & $\alpha_{1}$ & - & 0.0065 & 0.0065 & 0.0058 \\
\hline $\begin{array}{l}\text { coefficient } \\
\text { Ballast: }\end{array}$ & $\alpha_{2}$ & - & 1 & 1 & 0.89 \\
\hline Elastic modulus & $E_{\mathrm{b}}$ & $\mathrm{MPa}$ & 19 & 100 & $276\left(138-551^{\#}\right)$ \\
\hline Poisson's ratio & $v_{\mathrm{b}}$ & - & 0.49 & 0.3 & 0.3 \\
\hline $\begin{array}{l}\text { Density } \\
\text { Capping: }\end{array}$ & $\rho_{\mathrm{b}}$ & $\mathrm{kg} / \mathrm{m}^{3}$ & 1500 & 1800 & 1760 \\
\hline Elastic modulus & $E_{\mathrm{c}}$ & $\mathrm{MPa}$ & 20 & 220 & $138\left(69-276^{\#}\right)$ \\
\hline Poisson's ratio & $v_{\mathrm{c}}$ & - & 0.5 & 0.3 & 0.35 \\
\hline $\begin{array}{l}\text { Density } \\
\text { Subgrade: }\end{array}$ & $\rho_{\mathrm{c}}$ & $\mathrm{kg} / \mathrm{m}^{3}$ & 1430 & 2175 & 1920 \\
\hline Elastic modulus & $E_{\mathrm{s}}$ & $\mathrm{MPa}$ & 44 & 27000 & $14\left(14-276^{\#}\right)$ \\
\hline Poisson's ratio & $v_{\mathrm{s}}$ & - & 0.5 & 0.25 & 0.35 \\
\hline Density & $\rho_{\mathrm{s}}$ & $\mathrm{kg} / \mathrm{m}^{3}$ & 1475 & 2300 & 1920 \\
\hline
\end{tabular}

Note: "Values indicate the range used for the parametric study.

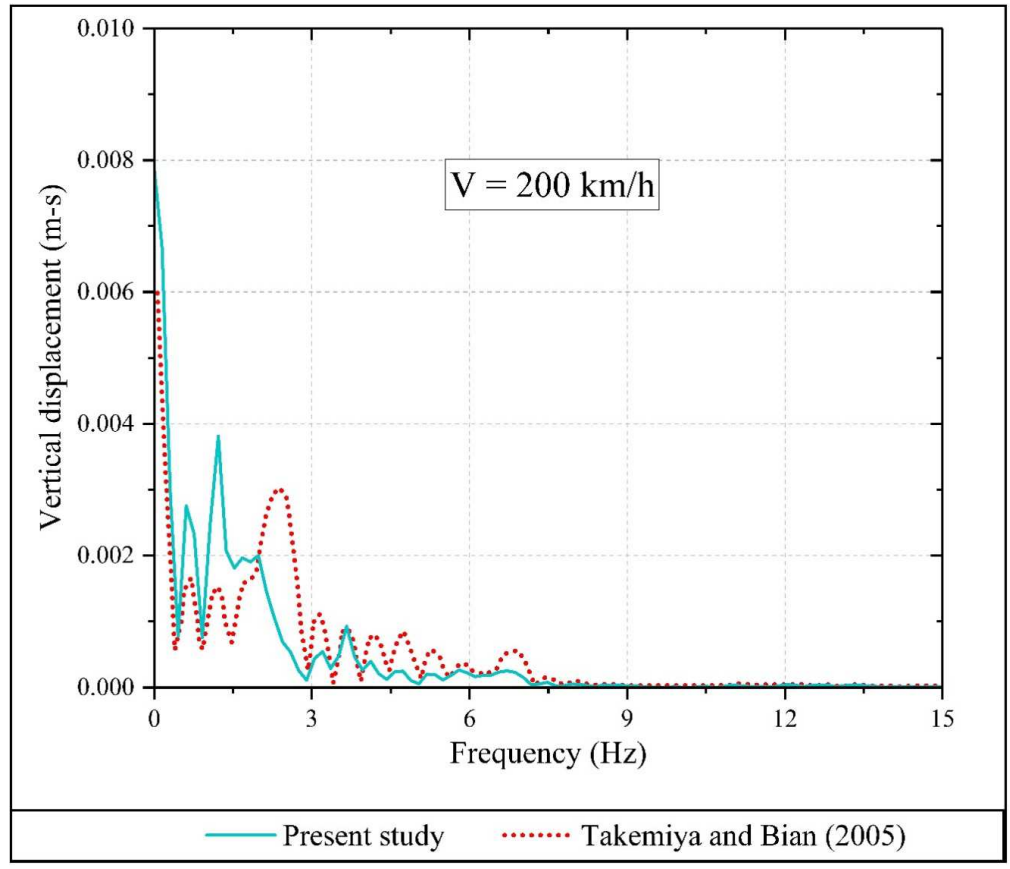

Fig. 3. Comparison of Fourier amplitudes of vertical ground displacement evaluated using the present approach with field data reported by Takemiya and Bian [25]. 
Thus, the present approach can accurately evaluate the transient or short-term response of the track substructure layers. This method can be employed to optimize track performance, improve the efficiency and consequently, reduce the operating cost of the railways. This approach may be of great interest to the practicing railway engineers owing to the simplicity and less computational power requirements.

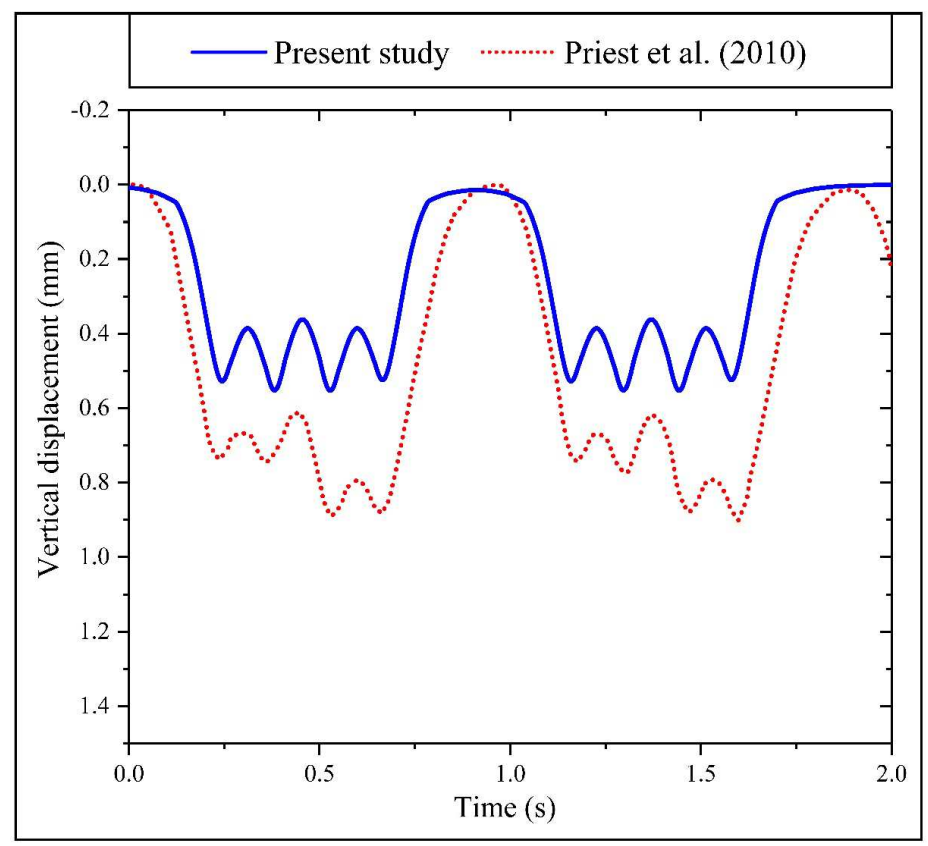

Fig. 4. Comparison of transient displacement evaluated using the present approach with field data reported by Priest et al. [26]

\section{$4 \quad$ Parametric study}

The proposed model is used to investigate the influence of elastic modulus on the transient response of track substructure layers. The elastic modulus of ballast $\left(E_{\mathrm{b}}\right)$, capping $\left(E_{\mathrm{c}}\right)$ and subgrade $\left(E_{\mathrm{s}}\right)$ is varied in the range of $138-551 \mathrm{MPa}, 69-276 \mathrm{MPa}$ and $14-276$ $\mathrm{MPa}$, respectively. A similar range of values has also been used by [27-29] in their parametric investigations. The track response is evaluated in terms of average recoverable vertical strain, which is the ratio of vertical deformation to the initial thickness of the substructure layer. The predictions are carried out for the Thalys high-speed train travelling at a speed of $150 \mathrm{~km} / \mathrm{h}$.

Fig. 5 shows the variation of average recoverable strain in the ballast, capping and subgrade layers with elastic moduli $E_{\mathrm{b}}, E_{\mathrm{c}}$ and $E_{\mathrm{s}}$. The values of parameters used in the prediction are given in Table 1. The horizontal dashed line in the figure represents the strain when the parameters are assigned the nominal values. The downward (blue) and 
upward (red) arrows indicate a reduction and increment in strain, respectively. The results indicate that the average recoverable strain in the ballast and capping layers decrease by $77.9 \%$ and $7.9 \%$, respectively, with a rise in $E_{\mathrm{b}}$ from $138-551 \mathrm{MPa}$. The subgrade layer showed a marginal effect. This reduction in resilient response is attributed to the increase in stiffness of ballast layer (consequently, an increment in load distribution area) with a rise in the elastic modulus.

The recoverable strain in the ballast layer increases by $17 \%$ with a rise in $E_{\mathrm{c}}$ from 69-276 MPa. Whereas, the strain in the capping layer decreases by $73 \%$ with an increase in $E_{\mathrm{c}}$ from 69-276 MPa. The capping modulus has an insignificant influence on the subgrade strain. The average recoverable strain in the subgrade layer decreases by $73 \%$ with a rise in $E_{\mathrm{s}}$ from $14-276 \mathrm{MPa}$. However, the recoverable strain in the ballast and capping layers increases by $69 \%$ and $70 \%$, respectively with a rise in $E_{\mathrm{s}}$ from 14 $276 \mathrm{MPa}$. This indicates that the presence of a stiff subgrade may increase the deformation in the granular (ballast and capping) layers.

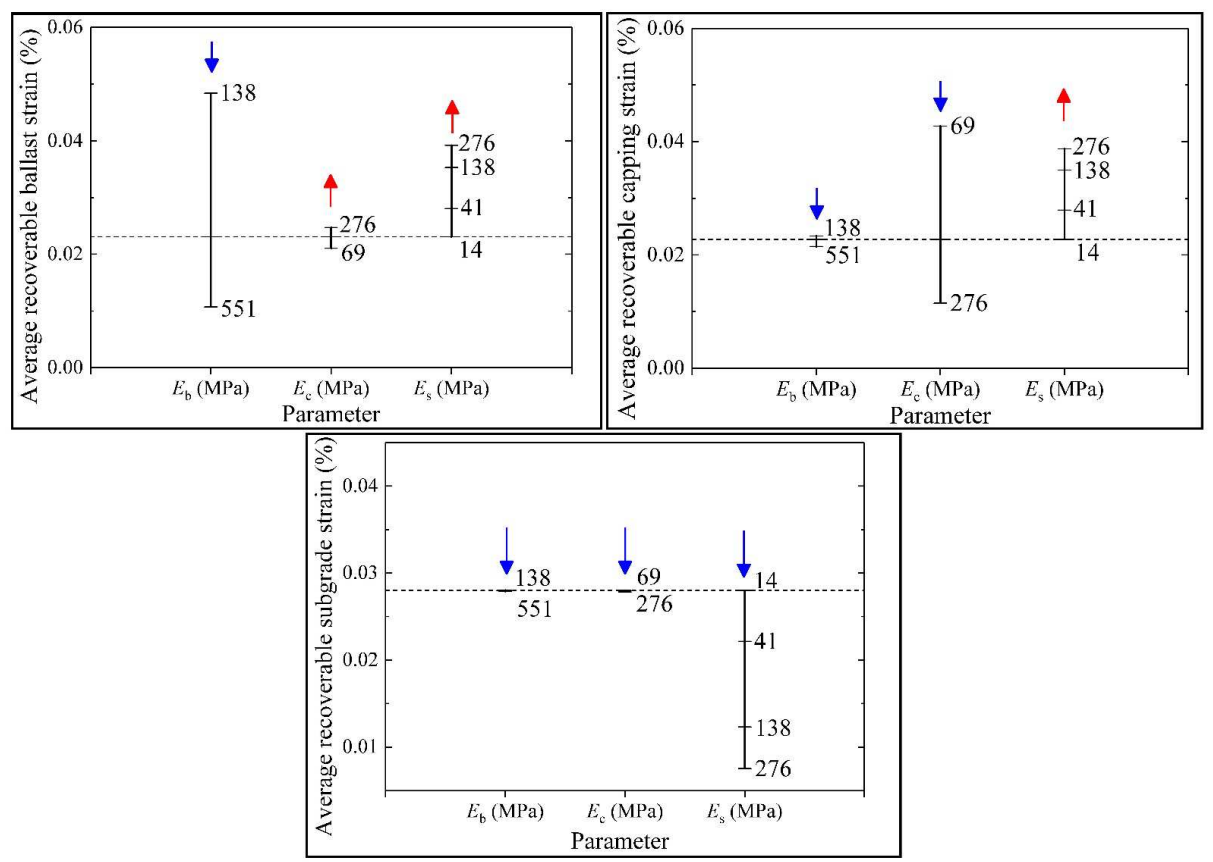

Fig. 5. Influence of elastic modulus on the average transient vertical strain in the track substructure layers.

Therefore, it is clear that the elastic modulus of the substructure layers plays a significant role in the transient response of the railway track. The present approach can be used to evaluate the track response for different train, track and substructure properties. This analysis may provide the value of parameters that are required to achieve optimum track performance. 


\section{Conclusions}

An analytical method is developed to predict the transient response of substructure layers in ballasted railway tracks. The approach evaluates the recoverable response using a three degree of freedom mass-spring-dashpot model. The validity of the technique is examined by comparing the predicted results with the field investigation results reported in the literature. A close agreement between the observed and predicted results demonstrates the accuracy of the proposed approach in evaluating the track substructure response. The parametric study on the track behavior shows that the elastic modulus of track layers significantly influence their response. The presence of stiff subgrade may increase the deformation in the granular substructure layers (ballast and capping). The present approach can be adopted by railway engineers to improve track performance.

\section{References}

1. Nimbalkar, S., Indraratna, B.: Improved performance of ballasted rail track using geosynthetics and rubber shockmat. J. Geotech. Geoenviron. Eng. 142(8), 04016031 (2016).

2. Nguyen, K., Villalmanzo, D., Goicolea, J., Gabaldon, F.: A computational procedure for prediction of ballasted track profile degradation under railway traffic loading. Proc. Inst. Mech. Eng. F J. Rail Rapid Transit 230(8), 1812-1827 (2016).

3. Stewart, H., Selig, E.: Predicted and measured resilient response of track. Journal of Geotechnical Engineering Division 108(11), 1423-1442 (1982).

4. Yang, Y.B., Hung, H.H.: A 2.5D finite/infinite element approach for modelling visco-elastic bodies subjected to moving loads. Int. J. Numer. Methods Eng. 51(11), 1317-1336 (2001).

5. Hall, L.: Simulations and analyses of train-induced ground vibrations in finite element models. Soil Dyn. Earthquake Eng. 23(5), 403-413 (2003).

6. Yang, L.A., Powrie, W., Priest, J.A.: Dynamic stress analysis of a ballasted railway track bed during train passage. J. Geotech. Geoenviron. Eng. 135(5), 680-689 (2009).

7. Bian, X., Jiang, H., Chen, Y.: Accumulative deformation in railway track induced by highspeed traffic loading of the trains. Earthq. Eng. Eng. Vib. 9(3), 319-326 (2010).

8. Galvín, P., Romero, A., Domínguez, J.: Fully three-dimensional analysis of high-speed train-track-soil-structure dynamic interaction. J. Sound Vib. 329(24), 5147-5163 (2010).

9. Banimahd, M., Woodward, P., Kennedy, J., Medero, G.: Three-dimensional modelling of high speed ballasted railway tracks. Proc. Inst. Civ. Eng. Transp. 166(2), 113-123 (2013).

10. Connolly, D., Giannopoulos, A., Forde, M.: Numerical modelling of ground borne vibrations from high speed rail lines on embankments. Soil Dyn. Earthquake Eng. 46, 13-19 (2013).

11. Chen, J., Zhou, Y.: Dynamic responses of subgrade under double-line high-speed railway. Soil Dyn. Earthquake Eng. 110, 1-12 (2018).

12. Li, L., Nimbalkar, S., Zhong, R.: Finite element model of ballasted railway with infinite boundaries considering effects of moving train loads and Rayleigh waves. Soil Dyn. Earthquake Eng. 114, 147-153 (2018).

13. Metrikine, A.V., Popp, K.: Vibration of a periodically supported beam on an elastic halfspace. Eur. J. Mech. A. Solids 18(4), 679-701 (1999).

14. Chen, Y.H., Huang, Y.H.: Dynamic stiffness of infinite Timoshenko beam on viscoelastic foundation in moving co-ordinate. Int. J. Numer. Methods Eng. 48(1), 1-18 (2000). 
15. Kaynia, A.M., Madshus, C., Zackrisson, P.: Ground vibration from high-speed trains: Prediction and countermeasure. J. Geotech. Geoenviron. Eng. 126(6), 531-537 (2000).

16. Guo, Y., Zhai, W.: Long-term prediction of track geometry degradation in high-speed vehicle-ballastless track system due to differential subgrade settlement. Soil Dyn. Earthquake Eng. 113, 1-11 (2018).

17. Dieterman, H., Metrikine, V.: Steady-state displacements of a beam on an elastic half-space due to a uniformly moving constant load. Eur. J. Mech. A. Solids 16(2), 295-306 (1997).

18. Sheng, X., Jones, C.J.C., Petyt, M.: Ground vibration generated by a harmonic load acting on a railway track. J. Sound Vib. 225(1), 3-28 (1999).

19. Choudhury, D., Bharti, R.K., Chauhan, S., Indraratna, B.: Response of multilayer foundation system beneath railway track under cyclic loading. J. Geotech. Geoenviron. Eng. 134(10), 1558-1563 (2008).

20. Ahlbeck, D.R., Meacham, H.C., Prause, R.H.: The development of analytical models for railroad track dynamics. In: Symp. on Railroad Track Mechanics. Pergamon Press, Princeton University. p. 239-263 (1975).

21. Zhai, W.M., Wang, K.Y., Lin, J.H.: Modelling and experiment of railway ballast vibrations. J. Sound Vib. 270(4-5), 673-683 (2004).

22. Nimbalkar, S., Indraratna, B., Dash, S.K., Christie, D.: Improved performance of railway ballast under impact loads using shock mats. J. Geotech. Geoenviron. Eng. 138(3), 281-294 (2012).

23. Doyle, N.F.: Railway track design a review of current practice. In, B.o.T. Economics, Editor. Australian government publishing service, Canberra (1980).

24. Esveld, C.: Modern railway track. MRT-Productions, Delft, The Netherlands (2001).

25. Takemiya, H., Bian, X.: Substructure simulation of inhomogeneous track and layered ground dynamic interaction under train passage. J. Eng. Mech. 131(7), 699-711 (2005).

26. Priest, J.A., Powrie, W., Yang, L., Grabe, P.J., Clayton, C.R.I.: Measurements of transient ground movements below a ballasted railway line. Géotechnique 60(9), 667-677 (2010).

27. Selig, E.T., Li, D.: Track modulus: Its meaning and factors influencing it. Transp. Res. Rec. 1470, 47-54 (1994).

28. Shahu, J., Kameswara Rao, N., Yudhbir: Parametric study of resilient response of tracks with a sub-ballast layer. Can. Geotech. J. 36(6), 1137-1150 (1999).

29. Li, D., Hyslip, J., Sussmann, T., Chrismer, S.: Railway geotechnics.Taylor and Francis, Boca Raton, USA (2016). 